\title{
Penerapan Prinsip-Prinsip Seni Rupa Pada Kaligrafi Di Masjid Baiturrahman Unimed
}

\section{Application Of Principles Of Fine Art To Calligraphy At The Unimed Baiturrahman Mosque}

\author{
Joko Tri Utoyo*, Agus Priyatno \& Adek Cerah Kurnia Azis \\ Program Studi Pendidikan Seni Rupa, Jurusan Seni Rupa Fakultas Bahasa Dan Seni \\ Universitas Negeri Medan, Indonesia
}

Diterima: 01 September 2020; Direview: 02 September 2020; Disetujui: 13 September 2020 *Coresponding Email: jokotriutoyo9@gmail.com

\begin{abstract}
Abstrak
Penelitian ini bertujuan untuk mengetahui hasil penerapan prinsip-prinsip seni rupa pada beberapa kaligrafi di masjid Baiturrahman Unimed. Penelitian ini menggunakan metode rattil (merapikan, menyusun, menertibkan) untuk mencari seberapa dalam penerapan prinsip seni yang dipakai dalam kaligrafi, dan jenis kaligrafi yang dipakai. Kaligrafi yang di ambil untuk diteliti menggunakan metode deskriptif kualitatif yang dengan cara ini peneliti akan menjabarkan dan mendeskripsikan segala aspek yang berkaitan dengan proporsi, keseimbangan, irama, kejelasan, dan kesatuan. Maka dengan metode ini akan dapat diketahui tentang prinsip seni dan desain pada kaligrafi. Instrumen penelitian ini menggunakan kamera dan scanner sebagai dokumentasi dan lembar penilaian berupa tabel dari indikator berdasarkan prinsip seni rupa yang dibatasi hanya pada lima (5) aspek saja. Tehnik pengumpulan data dilakukan dengan melakukan observasi, dokumentasi, dan studi pustaka yang berkaitan dengan topik penelitian. Dan dari sampel yang diambil diketahui jenis khat yang dipakai yaitu khat Naskhi, Riq'ah, dan Tsuluts. Secara keseluruhan penerapan prinsip-prinsip seni rupa pada kaligrafi di masjid baiturrahman unimed memiliki elemen dari nilai aspek proporsi kemudian aspek keseimbangan, aspek irama, diikuti dengan aspek kejelasan, dan aspek yang terakhir adalah kesatuan dari kelima elemen tersebut ternyata pada penerapannya tidak didapati keutuhan dan kesempurnaan elemen dan desainnya yang berarti bahwa dalam penerapanya masih kurang baik.
\end{abstract}

Kata kunci : Prinsip-Prinsip Seni Rupa, Kaligrafi

\begin{abstract}
This study aims to determine the results of applying the principles of fine arts to some calligraphy at the Baiturrahman Unimed mosque. This study uses the rattil method (tidying up, arranging, order) to find out how deep the application of the principles of art used in calligraphy, and the type of calligraphy used. Calligraphy that is taken for research uses a qualitative descriptive method in which the researcher will describe and describe all aspects related to proportion, balance, rhythm, clarity, and unity. So with this method it will be known about the principles of art and design in calligraphy. This research instrument uses a camera and scanner as documentation and an assessment sheet in the form of a table of indicators based on the principles of fine arts which is limited to only five (5) aspects. Data collection techniques are carried out by making observations, documentation, and literature studies related to the research topic. And from the sample taken, it is known that the type of khat used is the Naskhi, Riq'ah, and Tsuluts khat. Overall the application of the principles of fine art in calligraphy at the Baiturrahman Unimed mosque has elements from the value of the proportion aspect then the aspect of balance, the aspect of rhythm, followed by the aspect of clarity, and the last aspect is the unity of the five elements, it turns out that in its application there is no wholeness and perfection elements and design which means that the application is still not good.
\end{abstract}

Keywords : Calligraphy, Principles Of Fine Art

How to Cite: Utoyo, J.T., Priyatno, A., \& Azis, A.C.K., (2020). Penerapan Prinsip-Prinsip Seni Rupa Pada Kaligrafi di Masjid Baiturrahan Unimed. Journal of Education, Humaniora and Social Sciences (JEHSS). 3 (2): 419-426. 


\section{PENDAHULUAN}

Prinsip seni rupa merupakan landasan dalam membuat karya seni, dalam suatu karya seni yang dapat dinikmati dari segi estetik dan sedap dipandang mata merupakan karya seni yang menerapkan prinsip-prinsip seni rupa. Prinsip seni rupa itu sendiri adalah cara dalam menyusun/menata beberapa unsur-unsur rupa, seperti titik, garis, bidang, ruang, bentuk, gelap terang, tekstur, dan warna. Kedelapan unsur ini kemudian di tata kembali didalam prinsipprinsip seni rupa agar menjadi suatu karya seni yang umumnya terdiri dari, kesatuan, keseimbangan, irama, proporsi, keselarasan, pusat perhatian, komposisi, dan gradasi (Rusdi et al., 2020; Risvantry et al., 2020; Mustika at al., 2020).

Dalam karya seni kaligrafi (Sirojuddin, 2016) Ubaidullah bin Al-Abbas menyebutnya sebagai lisan al-yadd (lidahnya tangan) karena dengan tulisan itulah tangan berbicara. Sering ditekankan mengenai tata cara penulisan baik dari luar (unsurunsur rupa) maupun dari dalam (prinsip-prinsip rupa) yang menjadi sebuah tolak ukur untuk mencapai kesempurnaan dalam membuat karya seni kaligrafi, tanpa harus meninggalkan prinsip-prinsip kaligrafi itu sendiri. Dayudin,Rohendi dalam bukunya (2018) Menurut Ibnu Muqlah bentuk sebuah tulisan (Naskh) akan dianggap benar jika memiliki lima kriteria, yaitu; taufiyah (tepat), itman (tuntas), ikmal (sempurna), isyba (padat), dan irsal (lancar)

Pada bidang seni hiasan, kerajinan, dan tulisan kaligrafi, penciptaan serta pengadaan karya seni tersebut adalah untuk mengangkat keagungan syi'ar Islam ke tengah arena kehidupan masyarakat sementara pada pengadaan karya seni yang membentuk wujud atau penggambaran makhluk hidup tidak dibenarkan dengan kata lain Penolakan penggambaran figuratif karena dapat mengarah pada penyembahan berhala, menyebabkan kaligrafi dan penggambaran abstrak menjadi bentuk utama ekspresi seni dalam berbagai budaya Islam, khususnya dalam konteks keagamaan. Sebagai contoh, kaligrafi nama Tuhan diperkenankan sementara penggambaran figuratif tuhan tidak diizinkan (Blair, Sheila; Bloom, Jonathan, 1995).

Dijelaskan bahwa ada tujuh prinsip-prinsip dasar seni rupa dan desain, meliputi antara lain keselarasan/irama/ritme, kesatuan (unity), dominasi/daya tarik/pusat perhatian, keseimbangan, keserasian/proporsi/perbandingan, kesederhanaan, dan kejelasan (Paramita et al., 2020; Agustin et al., 2020; Utami et al., 2020; Sinaga et al., 2020). Dengan adanya masalah mengenai prinsip seni rupa yang ada pada karya seni kaligrafi tersebut tentulah nilai keelokkan kaligrafi itu masi perlu dipertimbangkan sebab karya visual seperti kaligrafi harus memenuhi standart dan kaidah agar tidak melenceng dari arti dan makna pada tulisannya, selain itu juga pada penerapannya yang ada didalam prinsip-prinsip seni rupa (Sajiman, 2009).

Dalam penerapannya kaligrafi memiliki beberapa aturan dan fungsi-fungsi yang meliputi penerapannya, yaitu sebagai media komunikasi, dan penenang bagi hati seorang mukmin bila membacanya. Kaligrafi yang terdapat di dalam mesjid biasanya merupakan kutipan ayat-ayat Al-Qur'an yang dipilih dalam beberapa ayat yang berhubungan dengan kaitan perintah-perintah shalat, dan ketundukan seorang Muslim kepada sang pencipta Allah SWT. Quraisy Shihab dalam Suhairi (2019) berpendapat, Masjid dalam pengertiannya adalah tempat shalat umat islam, namun akar katanya mengandung makna "tunduk dan patuh", karena itu hakikat Masjid adalah tempat melakukan aktivitas apapun yang mengandung kepatuhan kepada Allah Subhanahu wa ta'ala".

Seperti pada bangunan Masjid Baiturrahman yang terletak di dalam lingkungan kampus Unimed berada di Jalan Williem Iskandar, Psr V, Medan Estate, Kecamatan Percut Sei Tuan, Kabupaten Deli Serdang Provinsi Sumatera Utara, yang di bangun di 
atas tanah seluas $2570 \mathrm{~m}^{2}$ setelah mengalami renovasi. Masjid Baiturrahman memiliki satu kubah besar dan dua kubah kecil terletak dibagian luar atas bangunan masjid yang terdapat tulisan kaligrafi pada bagian luar kubahnya, dan satu menara juga terdapat tulisan kaligrafi pada bagian luar kubahnya, juga memiliki ruang jama'ah yang cukup luas, ditambah pada bagian lantai dua terdapat ruang untuk jama'ah wanita. Di bagian dalam masjid terdapat delapan buah tiang dan tulisan kaligrafi berbahan kayu, kuningan, dan aluminium yang didesain berukuran dan bentuk yang bervariasi juga berbeda jenis dan penulisannya. Kaligrafi inilah yang menjadi objek penelitian oleh peneliti. Masjid yang memiliki ukuran yang cukup luas dan mampu menampung banyak jama'ah ini memiliki arsitektur bergaya timur tengah, dan diantara pengunjung yang datang tidak banyak yang mengetahui tentang jenis kaligrafi pada masjid Baiturrahman tersebut. Quraisy Shihab dalam Suhairi (2019) berpendapat, Masjid dalam pengertiannya adalah tempat shalat umat islam, namun akar katanya mengandung makna "tunduk dan patuh", karena itu hakikat Masjid adalah tempat melakukan aktivitas apapun yang mengandung kepatuhan kepada Allah Subhanahu wa ta'ala". Ditambah dengan adanya renovasi pada bagian masjid membuat gaya kaligrafi yang di terapkan mulai tidak sesuai dengan model bangunan, dan juga beberapa jenis kaligrafi yang tidak sesuai dengan kaidah penulisan kaligrafi, juga warna-warna yang kurang selaras pada kaligrafi. Dalam hal ini peneliti ingin membuka atau meneliti jenis kaligrafi dan penerapan prinsip seni secara spesifik dan mendetail, agar masyarakat dan pengunjung nantinya lebih memahami tentang kaligrafi yang diterapkan pada masjid baiturrahman.

Kaligrafi merupakan salah satu hasil karya seni rupa yang memiliki nilai keelokkan, keanggunan, kewibawaan, dan ketegasan pada tiap hurufnya sehingga menjadi sebuah karya seni yang dapat dinikmati dan di pahami dalam bentuk jasmani dan rohani. Seni kaligrafi atau khat dilukiskan sebagai kecantikan rasa, duta akal, penasehat pikiran, senjata pengetahuan, penjinak saudara dalam pertikaian, pembicaraan jarak jauh, penyimpan rahasia, dan khazanah rupa-rupa masalah (Sirojuddin 2016). Subarna (2007) menjelaskan bahwa kaligrafi pada arsitektur Islam banyak mempengaruhi inskripsi pada sejumlah gereja.

Berdasarkan pemaparan latar belakang di atas, maka penulis tertarik untuk melakukan penelitian dengan menganalisis bagaimana penerapan prinsip-prinsip seni rupa pada Masjid Biturrahman Unimed dengan judul "Penerapan Prinsip-prinsip Seni Rupa pada Kaligrafi di Masjid Baiturrahman Unimed”.

\section{METODE PENELITIAN}

Untuk menjawab permasalahan yang ada dalam penelitian ini tentang "Penerapan Prinsip-Prinsip Seni Rupa Pada Kaligrafi di Masjid Biturrahman Unimed", maka metode yang dilakukan adalah pendekatan deskriptif dan teknik analisis kualitatif. Metode yang digunakan dalam penelitian ini adalah metode kulitatif, dan teknik pengumpulan data yang digunakan adalah Participant Observation (observasi berperan serta), dokumentasi, dan studi pustaka yang dikaitkan dengan tahap tingkatan lapangan, guna menjalankan keberhasilan suatu tindakan penelitian. Serta merta penelitian dengan pendekatan kualitatif bersifat deskriptif, yaitu mengadakan pengamatan langsung pada objek penelitian terhadap seluruh bentuk karya Kaligrafi pada desain Masjid Baiturrahman Unimed, kemudian mengumpulkan data berupa pengambilan gambar atau foto dari setiap desain kaligrafi yang ada pada Masjid Baiturrahman, dan melakukan pengumpulan data dan informasi dengan melakukan kegiatan kepustakaan melalui 
buku-buku, jurnal, ensiklopedia, sumber-sumber tertulis cetak, maupun penelitian terdahulu.

Penelitian ini bersifat menjelaskan makna dan keadaan yang sebenarnya pada karya-karya kaligrafi. Sugiyono (2015) memaparkan bahwa metode penelitian kualitatif adalah metode penelitian yang berlandaskan pada filsafat postpositivisme.

Peneliti menggunakan terapan metode rattil (menyusun/merapikan) guna memfokuskan pada tiap-tiap objek karya kaligrafi bagian demi bagian huruf dan desainnya.

Adapun urutan pelaksanaan Metode yang diterapkan dalam penelitian ini dapat dilihat, sebagai berikut: 1) Tahap persiapan: Pada bagian ini dimulai dengan mempersiapkan seluruh komponen/peralatan seperti camera scanner, lembar catatan, dan jadwal yang disepakati antara si peneliti dan pihak BKM Masjid guna melakukan sebuah wawancara; 2) Tahap pelaksanaan: Langkah-langkah pelaksanaan metode rattil dalam penelitian terhadap prinsip-prinsip seni rupa yang ada pada desain kaligrafi yaitu : Langkah pertama, Dalam langkah ini hal yang pertama dilakukan mengambil seluruh model desain kaligrafi sebagai bahan dalam bentuk data visual berupa gambar atau foto yang diambil melalui camera, kemudian melaksanakan diskusi terhadap pihak BKM Masjid untuk diadakan kesepakatan dalam perbaikan apabila dalam penilaian terdapat desain kaligrafi yang tidak sesuai dalam hal penerapan sesuai prinsip-prinsip seni rupa: Langkah kedua, kemudian mengumpulkan seluruh komponen desain kaligrafi untuk diuji dalam penilaian berdasarkan pada nilai Proporsi pada huruf (yang mencangkup keseluruhan model dan jenis huruf), Keseimbangan pada huruf (yang mencangkup keseluruhan model dan jenis huruf), Irama pada huruf (yang mencangkup keseluruhan model dan jenis huruf), Kejelasan pada huruf (yang mencangkup keseluruhan model dan jenis huruf), dan Kesatuan pada huruf (yang mencangkup keseluruhan model dan jenis huruf). Yang disajikan dalam jenis-jenis kaligrafi yang berbeda. Hal ini guna mengetahui seberapa kuat penerapan prinsip-prinsip seni rupa yang ada pada karya kaligrafi tersebut dan kecenderungan pada jenis huruf apa yang luput dari prinsip-prinsip seni rupa.

\section{HASIL DAN PEMBAHASAN \\ Bahan Yang Diteliti}

Dapat dilihat pada bagian ini, ialah penampakan beberapa jenis kaligrafi yang terdapat pada bagian Masjid Baiturrahman Unimed, gambar satu (1) pada kaligrafi diamati bahwa jenis kaligrafi yang dipakai yaitu jenis kaligrafi (Khat) Tsuluts dengan pewarnaan huruf tinta berwarna emas dan latar belakang gelap hitam, kemudian pada gambar dua (2) diamati jenis kaligrafi (Khat) Riq'ah, pada gambar tiga (3) diamati jenis kaligrafi (Khat) Naskhi, pada gambar empat (4) dapat diamati jenis kaligrafi (Khat) Tsuluts, dan pada gambar lima (5) diamati jenis kaligrafi (Khat) Naskhi yang keseluruhannya diamati melalui metode rattil

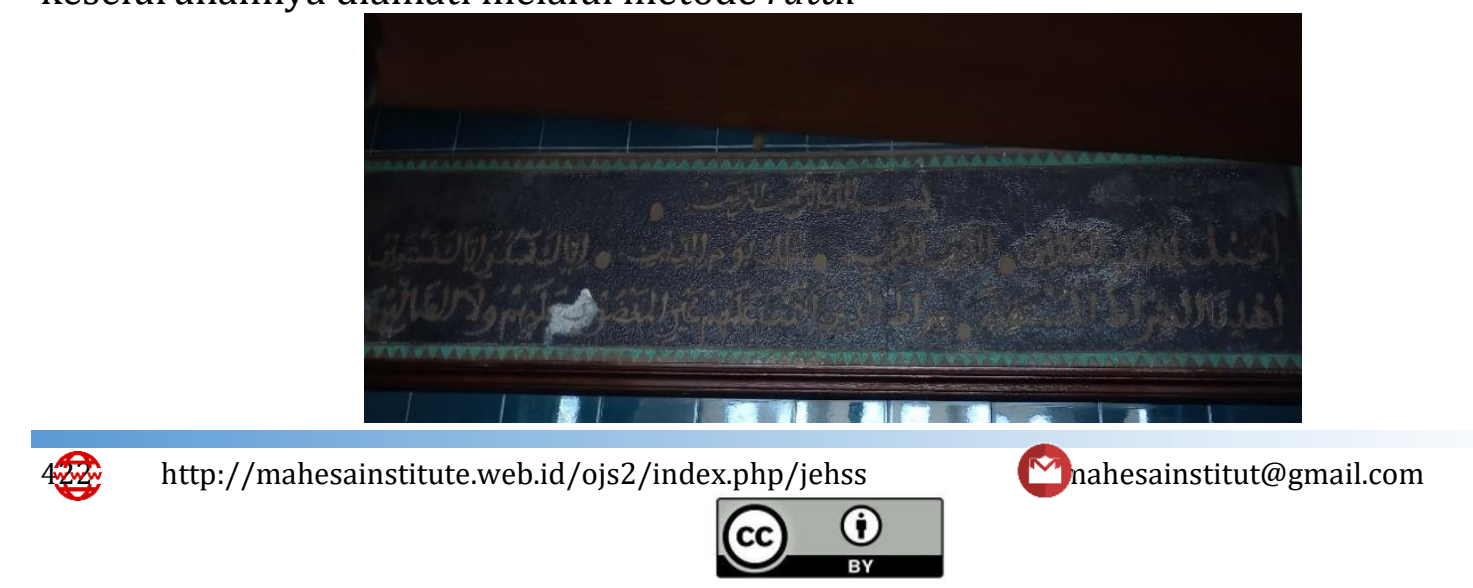




\section{Gambar 1. Kaligrafi Qs. Al-fatiha ayat 1-7}

Sumber gambar: Joko Tri Utoyo

Dalam gambar 1, dapat dilihat dan diamati bahwa kaligrafi ini memakai khat jenis tsuluts dan warna pada hurufnya memakai warna emas yang sudah hampir memudar, dengan balutan bingkai kayu serta hiasan bingkai berbentuk segitiga tersusun mengikuti alur bingkai, serta ditambah warna latar belakang (background) gelap hitam.

Diketahui bahwa pada prinsip seni rupa dan desain tulisan kaligrafi (arab) ini dalam proporsi masih mengalami distorsi yaitu perubahan panjang pada huruf 9 dan pada lebar huruf $د$ tidak sama, kemudian pada bagian keseimbangan pada desain dan penempatan tulisan sudah seimbang dan presisi, kemudian pada irama telah cukup untuk memenuhi elemen ini, elemen kesatuan dalam kaligrafi ini sudah terlihat konsistensi dan keutuhan pada tiap huruf kaligrafi sudah memenuhi dari elemen ini, kemudian pada kejelasan dari penulisan kaligrafi sudah jelas dan tidak sulit dimengerti hanya saja pemilihan warna dan desainnya yang membuat kaligrafi ini terlihat usang.

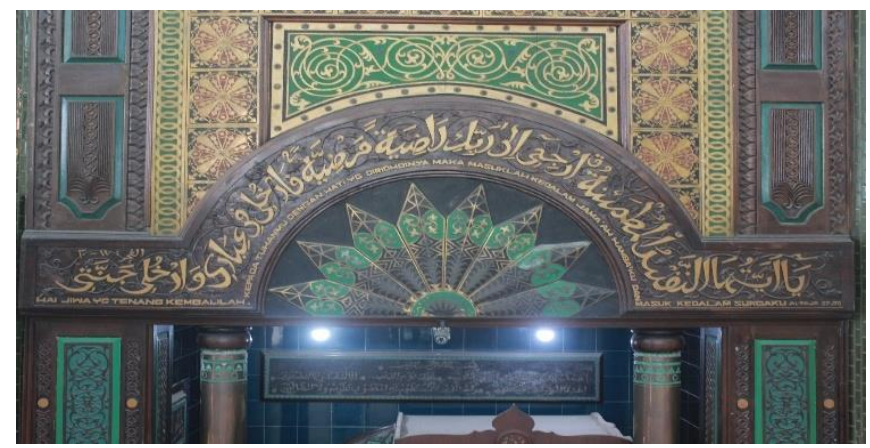

Gambar 2. Kaligrafi Qs. Al-fajr ayat 27-30

Sumber gambar: Joko Tri Utoyo

Dalam gambar 2, dapat dilihat dan diamati pada objek kaligrafi yang dalam penulisan memakai jenis khat Naskhi, terpajang di luar (bagian depan) dinding mihrab, pada kaligrafi warna kuning keemasan (golden yellow) dipadu dengan warna cokelat tua (dark brown) dengan desain yang sedikit unik dengan lekukan seperempat lingkaran mengikuti bentuk dari pada bangunan, juga terdapat tulisan arti dari pada kaligrafi ini.

Diketahui bahwa pada dasar prinsip seni rupa dan desain tulisan kaligrafi (arab) ini dalam penilaian proporsi dijelaskan bahwa setiap desain huruf pada tulisan kaligrafi ini juga masih ada distorsi pada huruf ta marbuta $\bullet$ yang lengkungan pada huruf tersebut belum sama, lalu pada elemen keseimbangan tulisan kaligrafi yang memiliki bentuk horizontal dan setengah melingkar ini sudah seimbang dalam pewarnaan dan pengambilan letak pada tulisan hurufnya sudah memenuhi dari elemen ini, kemudian pada elemen irama, pengulangan tulisan untuk bagian setengah lingkaran terlihat agak mengecil bila di bandingkan pada awal dan akhir dari ayat tersebut yang semestinya memiliki ukuran sama dari awal hingga diakhirnya, lalu pada elemen kesatuan konsistensi dalam penulisan kaligrafi ini belum memenuhi dan juga dalam keutuhannya masih terlihat kurang pas. Pada elemen kejelasan kaligrafi sudah tampak jelas untuk diketahui jenis kaligrafi, mudah untuk dibaca, dan mudah untuk di mengerti pemaknaan dari kaligrafi ini.

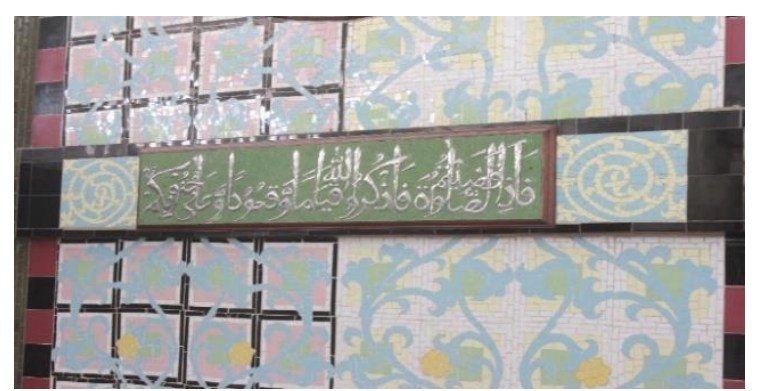

Gambar 3. Kaligrafi Qs. Annisa ayat 103 
Dalam gambar 3, dapat dilihat dan diamati penulisan yang dipakai pada kaligrafi ini dari jenis Khat Naskhi dengan tampilan warna pada tulisan berwarna silver dengan balutan bingkai kayu, pada kaligrafi ini memiliki warna hijau untuk latar belakang (background) panjang dari kaligrafi yang berbentuk horizontal ini dua (2) meter.

Diketahui bahwa pada dasar prinsip seni dan desain pada kaligrafi ini dalam penilaian proporsi masing-masing huruf sudah memenuhi kriteria ketebalan, panjang, dan lebar pada hurufnya sudah sesuai dan tidak terdapat distorsi, pada keseimbangan huruf dan pewarnaan sudah memenuhi kriteria dari elemen ini, lalu pada irama pengulangan huruf tulisan dalam kaligrafi ini masih kurang baik dapat dilihat pada kalimat yang awal "fa'i dza khadhaitumus 'shalah" kemudian "Allaha khiamaa" dan "wa'ala junuubikum" ketiganya masih belum sesuai untuk elemen pada irama dan pengambilan pengulangan pada huruf belum teratur, kemudian pada elemen kejelasan pada model huruf kaligrafi ini sudah memenuhi untuk dasar pada elemen ini karena huruf sudah sangat jelas terbaca, dan dapat diketahui pula arti dan makna dari kaligrafi ini, dan pada elemen kesatuan dari kaligrafi ini pada pendekatan keterikatan huruf, keterkaitan, dan kerapatan pada setiap hurufnya cukup untuk memenuhi pada elemen ini.

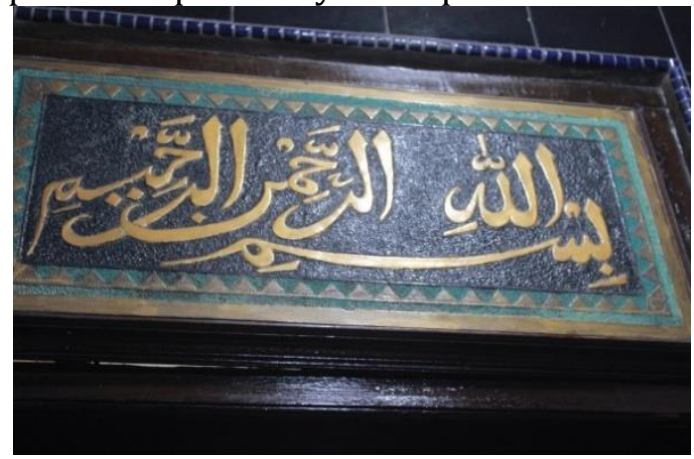

Gambar 4. Qs. An-Naml ayat 30

Sumber gambar: Joko Tri Utoyo

Dalam gambar 4, dapat dilihat dan diamati penulisan yang dipakai pada kaligrafi ini dari jenis Khat Tsuluts yang dipadukan warna tulisan berwarna kuning keemasan dengan balutan bingkai sederhana dengan bentuk segitiga tersusun dan garis biru ditengah yang mengelilingi dalam simetris bingkai, dan juga sentuhan warna gelap hitam pada pemilihan latar belakang (background) dan pada garis ujung bingkai yang berbentuk persegi diberi warna emas dengan bentuk garis mengikuti bentuk bingkai.

Diketahui bahwa pada dasar prinsip seni dan desain pada kaligrafi ini dalam penilaian proporsi untuk hurufnya terbilang kurang baik karena panjang, ketebalan dan lengkung dari huruf $\lrcorner$ tidak sama sementara untuk memenuhi kriteria dari pada elemen proporsi penulisan harus sesuai dan tidak boleh ada perubahan dan perbedaan dari penulisan huruf sebelumnya, juga pada keseimbangan untuk setiap hurufnya serta penempatannya yaitu pas keadaannya bila disesuaikan oleh bingkai yang meliputinya, dan sudah cukup terlihat simetris pada paduan hurufnya juga, kemudian pada elemen irama, pada bagian ini pengulangan serta lekukan pada huruf $\mathcal{J}$ tidak sama dan lebih hampir menyerupai huruf $\dot{u}$ karena panjang yang berubah dari huruf $\lrcorner$ yang sebelumnya, kemudian pada elemen kejelasan secara keseluruhan bacaan kaligrafi ini akan dapat mudah diketahui untuk tulisan dan bacaannya, namun bila dicermati kesalahan pada penulisan kaligrafi ini akan ditemukan seperti penjelasan diatas, dan pada elemen kesatuan dalam pendekatan kesamaan, keterikatan, keterkaitan, dan kerapatan dari tulisan dan pemilihan pewarnaan kaligrafi ini sudah memenuhi kriteria dari elemen kesatuan. 


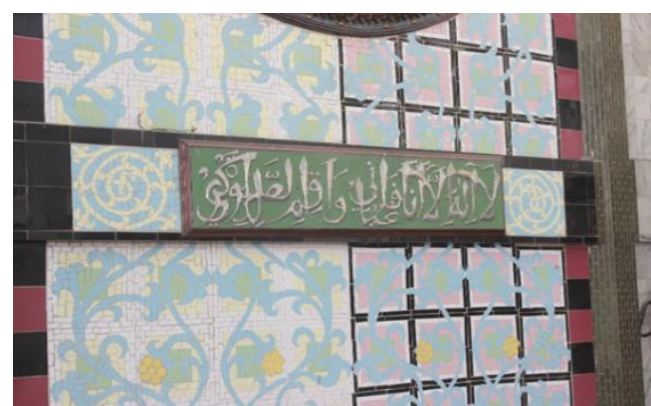

Gambar 5. Qs. Thaha ayat 14

Sumber gambar: Joko Tri Utoyo

Dalam gambar 5, dapat dilihat dan diamati penulisan yang dipakai pada kaligrafi ini dari jenis Khat Naskhi ukuran pada kaligrafi ini mencapai lebar dua (2) meter, kemudian dibalut dengan bingkai berwarna cokelat berbahan dasar kayu, dan pemilihan warna silver untuk tulisan kaligrafi ini ditambah warna hijau yang mendasari pada latar belakang (background), tidak ada hiasan pada bingkai yang dipakai untuk kaligrafi ini hanya bingkai polos yang sederhana, ini dibuat untuk memberikan kesan kesederhanaan pada kaligrafi ini.

Diketahui bahwa pada dasar prinsip seni dan desain kaligrafi ini dalam penilaian elemen proporsi bagian huruf ص lekukan yang menyerupai perut yang memiliki ruang didalamnya dari huruf tersebut terlalu kecil sehinga tidak menggambarkan atau menunjukan huruf yang sesuai atau yang dimaksud, juga pada huruf baca " fa'budu" tulisan ini hampir tak bisa terlihat dengan jelas karena huruf ini dibuat terlalukecil dengan bentuk tulisan yang tidak sesuai, lalu bagian elemen keseimbangan, huruf kaligrafi akan diJelaskan dalam keseimbangan sentral pada tulisan kaligrafi keseluruhan pada huruf yang dipakai cukup memenuhi karena pada keseimbangan sentral ini dilihat dari keseluruhan yang meliputi objek kaligrafi tersebut, dan pada keseimbangan diagonalnya juga keseluruhan pada huruf sudah memenuhi, dengan bentuk garis yang tegak rata. Lalu pada elemen irama, bagian huruf pada kaligrafi ini memiliki irama pengulangan tulisan yang kurang baik karena jarak kerapatan dan pengulangan huruf yang berubah tidak stabil, yaitu pada bagian bacaan huruf "fa'buduni wa akhimishala", dan terlalu rapat yang seolah bacaan tertimpa huruf yang sebelumnya yaitu pada bagian bacaan "shalata lidzikrii". Kemudian elemen kejelasan, pada elemen ini kejelasan dari kaligrafi ini ada beberapa yang tidak jelas atau hampir tidak bisa dimengerti maksud dari bacaannya yaitu bacaan "shalata lidzikrii" pada huruf $J$ penempatannya kurang pas sehingga hampir terkecoh bila dibaca, dan huruf د yang hampir tak terlihat hurufnya karena terlalu tipis. Lalu pada elemen kesatuan untuk kaligrafi ini pada keterikatan, keterkaitan, dan kerapatan hurufnya masih terbilang baik.

\section{SIMPULAN}

Berdasarkan hasil analisis data pada kaligrafi di Masjid Baiturrahman Unimed dalam penerapan prinsip-rinsip seni rupa dengan acuan pada elemen proporsi, keseimbangan, irama, kejelasan, dan kesatuan pada masing-masing kaligrafi yang diteliti tidak ada satupun dari jenis kaligrafi yang tidak menerapkan kelima elemen tersebut, hanya saja masih ada kekurangan pada kaligrafi untuk setiap elemen yang telah diteliti. Misal dari ketidak samaan huruf pada panjang, lebar, dan tebal kemudian kerapatan huruf, kejelasan untuk bagian huruf, penempatan huruf yang kurang sesuai, kesamaan pada huruf dalam pengulangan yang masi mengalami distorsi. Yang berarti dari hasil penelitian dalam pembahasan bahwa tidak semua jenis kaligrafi pada Interior Masjid Baiturrahman Unimed menerapkan Prinsip-prinsip seni rupa dengan baik.

\section{DAFTAR PUSTAKA}

Agustin, T., \& Ibrahim, A. (2020). Analisis Kaligrafi Kontemporer Dari Aspek Keterbacaan Huruf Dan Warna. Journal of Education, Humaniora and Social Sciences (JEHSS), 3(1), 187-192. doi:https://doi.org/10.34007/jehss.v3i1.251 
Bernard, L. (2009), Islam: the religion and the people. Philadelphia. Wharton School.

Blair, S.S. \& Bloom, J.M. (1995). The art and architecture of Islam. New Haven. Yale University.

Mustika, A., \& Erdansyah, F. (2020). Analisis Ornamen (Gerga) Tradisional Karo pada Bangunan Kantor Bupati Karo Kabupaten Karo. Journal of Education, Humaniora and Social Sciences (JEHSS), 3(1), 161-70. doi:https://doi.org/10.34007/jehss.v3i1.243

Paramita, N., Azmi, A., \& Azis, A. (2020). Upaya Meningkatkan Hasil Belajar Menggambar Bentuk Buah Teknik Krayon. Journal of Education, Humaniora and Social Sciences (JEHSS), 3(1), 171-177. doi:https://doi.org/10.34007/jehss.v3i1.245

Risvantry, U., \& Erdansyah, F. (2020). Analisis Desain Brosur Pendidikan pada Sekolah Dasar Islam Terpadu Al - Munadi Medan. Journal of Education, Humaniora and Social Sciences (JEHSS), 3(1), 153-160. doi:https://doi.org/10.34007/jehss.v3i1.242

Rohendi, A., dan Dayudin, (2018), METODE MAPAN, Bandung; Bahasa Dan Sastra Arab UIN Sunan Gunung Jati .

Rusdi, L., Soeprayogi, H., \& Mesra, M. (2020). Kerajinan Anyaman Bambu Di Sanggar Kreatif "Bunga Matahari" Kelurahan Rambung Barat Kecamatan Binjai Selatan. Journal of Education, Humaniora and Social Sciences (JEHSS), 3(1), 133-140. doi:https://doi.org/10.34007/jehss.v3i1.216

Sajiman. (2009), nirmana, elemen-elemen seni dan desain, Yogyakarta, Jalasutra

Sinaga, D., \& Triyanto, R. (2020). Tinjauan Ilustrasi Cover Novel Harry Potter Edisi Indonesia Karya Nicolas Fiber Ditinjau Dari Elemen Visual. Journal of Education, Humaniora and Social Sciences (JEHSS), 3(1), 265-272. doi:https://doi.org/10.34007/jehss.v3i1.292

Sirojuddin, A.R. (2016), Seni Kaligrafi Islam, Jakarta: AMZAH

Subarna, A.D. (2007), cakrawala lukisan kaligrafi islam di indonesia”. Visual Arts \#21.

Umar, S. (2019), Pendidikan Masyarakat Berbasis Masjid, Yogyakarta: Deepublish Publisher

Utami, A., Soeprayogi, H., \& Azis, A. (2020). Pembuatan Kerajinan Bunga Berbahan Kulit Jagung Ditinjau dari Prinsip-prinsip Seni Rupa dan Kerajinan. Journal of Education, Humaniora and Social Sciences (JEHSS), 3(1), 260-264. doi:https://doi.org/10.34007/jehss.v3i1.282 